\title{
A IMPORTÂNCIA DO SENTIDO NAS AULAS DE GEOGRAFIA: POSSÍVEIS CAMINHOS PARA UM RECONHECIMENTO ENTRE O SUJEITO E O MUNDO
}

\author{
The importance of sense in geography lessons: possible ways for a recognition between the \\ subject and the world \\ Diego Brandão Nunes* \\ Antonio Carlos Castrogiovanni ** \\ * Mestre em Geografia pelo PPG em Geografia/UFRGS - diego-brandaonunes@hotmail.com. \\ ** Docente do PPG em Geografia - castroge@ig.com.br.
}

Recebido em 15/08/2018. Aceito para publicação em 25/08/2018.

Versão online publicada em 03/09/2018 (http://seer.ufrgs.br/paraonde)

\section{Resumo:}

0 presente trabalho possui como tema a importância da presença ou não do sentido nas aulas de Geografia. Nossa delimitação analítica está pautada na relação do sentido como facilitador ou não do processo de ensinoaprendizagem em Geografia. 0 caminho investigativo emprega o Paradigma da Complexidade (Morin, 2011) como desafio para a compreensão do mundo pautado nas técnicas da Pesquisa Qualitativa. A pesquisa possui como preocupação inicial o estudo do conceito de sentido a fim de que tenhamos clareza epistemológica para buscarmos aproximações com as demandas da área do ensino de Geografia. A partir disso, problematizamos os desafios que encontramos nas salas de aula, as proximidades que esta ciência pode possuir com o estudo do sentido e investigamos as possibilidades que favorecem maior atribuição do mesmo por parte dos alunos.

Palavras-chave: Ensino de Geografia; Sentido, Logoterapia.

\begin{abstract}
:
The present work has as its theme the importance of presence, or not, of sense in the classes of Geography. Our analytical delimitation is based on the relation of sense as a facilitator or not of the teaching-learning process in Geography. The investigative path employs the Complexity Paradigm (Morin, 2011) as a challenge for understanding the world based on Qualitative Research techniques. The search has as initial preoccupation the study of the concept of sense in order that we have epistemological clarity to seek approximations with the demands of the area of the teaching of Geography. From this, we problematize the challenges that we find in classrooms, the proximity that this science can possess with the study of sense and investigate the possibilities that favor better attribution of the same by the students
\end{abstract}

Key-words: Geography Teaching, Sense; Logoterapy.

\section{Introdução: Por que buscar?}

A tarefa de ser professor de Geografia nos parece ser cada vez mais desafiante. Sendo esta, uma ciência preocupada com o estudo do espaço, possui a tarefa de buscar constantemente maneiras de (re)pensar o que vem sendo feito em nossas salas de aula. Este trabalho, fruto de nossa pesquisa de dissertação do Mestrado que ainda está em andamento, convida o leitor a refletir alguns pontos de sua prática docente e do próprio ensino de Geografia na contemporaneidade.

A escola, inserida em suas estruturas organizacionais geralmente rígidas, corre o risco de mostrar currículos com falta de diálogo e articulação entre os seus conteúdos programáticos. Não parece ser este um ambiente que atraia o jovem enquanto um espaço de aprendizagem. Poucos a veem como local de crescimento pessoal e aberta para novos conhecimentos, os não-formais e a própria integração entre saberes. 
Acreditamos, neste momento, que estas inquietudes, supracitadas, possuem antes, uma pergunta mais ampla: Quando é que uma aula de Geografia possui sentido para o aluno? Retomando nossas experiências enquanto estudantes de Geografia na Educação Básica e pensando nos momentos em que a disciplina conseguia se aproximar com maior competência das nossas realidades, parecia ser quando tratava dos problemas pelos quais conseguíamos vivenciar que ocorria uma construção mais fácil dos conteúdos nos quais a disciplina se propunha a ensinar. Não queríamos fugir dos problemas que enfrentávamos, queríamos buscar respostas para eles, a escola nem sempre conseguia fazer esse encontro entre o conhecimento ali construído e sua aplicação para a resolução de problemas. A Geografia nos parece ter, como poucas disciplinas a capacidade de aproximação entre sua proposta curricular e o que o aluno vive, pensamos, provisoriamente, que um dos caminhos para dotar uma aula de sentido é buscar tal aproximação.

Esta pesquisa é, parte, resultado de nossa inquietação docente maior: Como atribuir sentido às aulas de Geografia para os alunos? Ela é fruto de nossas experiências com a Geografia nas mais diferentes posições (alunos, bolsistas, professores, pós-graduandos), mas também são as considerações de amplas discussões com colegas que também, em algum momento tiveram esse questionamento sobre o sentido do ensinar Geografia e seu papel na escola, pensamos muitas vezes várias maneiras de ensinar, sem refletirmos como esse conhecimento é trabalhado e recebido pelo aluno, reproduzimos experiências sem refletir sobre elas, deixamos de ser professores e muitas vezes corremos o risco de nos tornarmos apenas oficineiros.

Vamos ao encontro dessa preocupação e buscamos, a partir da análise da presença de sentido nas aulas de Geografia buscarmos caminhos para o encontro do mesmo, construindo possibilidades o conhecimento geográfico, ao mesmo tempo que desenvolvemos técnicas para aulas com maior significado por parte dos alunos. 0 estudo do sentido em sala de aula exige que tenhamos uma leitura de mundo flexível e que considere diversas áreas do conhecimento, uma vez que para a definição e o estudo do conceito de sentido precisamos recorrer aos estudos da Psicologia, da Filosofia e também os próprios conceitos da Geografia, para entrelaçarmos teoricamente o conceito de sentido com os conceitos da Geografia recorremos ao método da Complexidade, formulado por Morin (2003), onde fugindo das verdades únicas dos conhecimentos, consideramos a provisoriedade dos saberes e suas complementaridades.

Considerando a complexidade da sala de aula e diferenciando, pautado em Morin (2003), a informação como dados prontos e o conhecimento como os dados problematizados em sala de aula, Castrogiovanni (2014) alerta para um ponto importante do estudo do sentido em sala de aula:

Neste sentido, tenho observado que muitos dos profissionais da educação geográfica lidam com informações, desprezam os conhecimentos e não se preocupam com as competências. Essa atitude, pela minha leitura, torna os momentos pedagógicos desinteressantes, pois não encaminha à construção de sentido. É fácil constatarmos que há uma degradação do conhecimento pela informação (2014,p. 180. Grifo nosso).

O autor vai ao encontro de nossas inquietudes pedagógicas ao apontar o pouco cuidado diante do trabalho com o conhecimento e consequente falta de sentido na aula apresentada, voltamos às preocupações iniciais que motivaram nosso discurso: Sem a preocupação com a presença do sentido nos parece que trabalhamos de modo automático e despreocupados com nosso objetivo de construir a compreensão do espaço no qual trabalhamos. É preciso, acreditamos neste momento, dentro da luneta teórica da complexidade, analisarmos aproximações entre o estudo do sentido e a Geografia.

\section{Desenvolvimento: Por que a preocupação com o sentido da Geografia}

Quando refletimos sobre nossa experiência docente, percebemos que pautam nossas ações, a 
necessidade de constantes retomadas e reflexões sobre o que fora trabalhado, tomam conta de nossas análises as avaliações do que possa ter tido maior repercussão com os alunos ou também, as atividades que porventura, não tenham ocorrido exatamente como esperávamos (será que alguma consegue isso?), nos parece que os debates sobre práticas de ensino em Geografia têm propiciado cada vez mais estas trocas de experiências, ficando evidente o quanto a discussão contínua e a reflexão do que temos feito são salutares para nossas escolas e oxigenam nossas salas de aula, buscando uma fuga do senso-comum.

Pretendemos, dentro dessa problematização e reflexão acerca da importância, ou não, do sentido nas aulas de Geografia, irmos ao encontro também, dos professores que, assim como seus alunos, muitas vezes já não percebem a importância de lecionar tal ciência, pensamos que tais significações possam também aproximar a vida de quem trabalha com a Geografia para dentro de suas aulas, fazendo com que a disciplina esteja inserida nas experiências de quem ensina e de quem aprende. Corremos o risco, enquanto profissionais, de estarmos trabalhando de maneira automática, repetindo planos de aulas, sem considerarmos o quanto o nosso aluno muda a cada ano, a cada semestre, a cada dia! Acreditamos, neste momento, que o caminho do ensinar Geografia se faz dentro de dois pontos: A segurança na fundamentação do trabalho do professor e a resposta, ou não, dos alunos, diante das atividades propostas.

Cabe salientar que, pensando na lógica do professor da educação básica, pautados nas experiências que tivemos, um discurso recorrente e que vai ao encontro das preocupações desta pesquisa está no desânimo discente no aprender, a falta de motivação nos jovens que não apresentam reação diante de qualquer manifestação do seu professor sobre o que será ensinado ou das atividades propostas. Tal situação vai ao encontro de uma das preocupações de Frankl (2008), autor da Logoterapia (linha da Psicoterapia voltada ao tratamento da superação de traumas a partir do sentido que as pessoas dão às suas vidas) quanto à vontade (ou falta dela) que existe nos sujeitos perante às situações de suas vidas. Para ele, a chamada "liberdade da vontade" é fundamental para compreender a presença do sentido na vida dos sujeitos, Guardini (2014), ao refletir sobre o uso da vontade na Logoterapia, recorda que "esse ser facultativo permite transformar uma possibilidade em realidade, em ação. Assim, o homem não é apenas um ser livre em potencial, mas um ser que decide", cabe a nós, pensando, na importância que tem para o aluno seu poder de tomadas de decisões e do desenvolvimento de sua autonomia promovêlas em nossas aulas, até mesmo, para poderem terem segurança para a formação de suas opiniões e defesa de ideias .

Encontramo-nos com as relações espaciais desde nossa pequena infância, porém, a "vemos" com maior clareza quando nos deparamos com sua sistematização em sua forma escolar, dentro do estudo da Geografia. Qual seria o motivo desta encantar a alguns e não gerar interesse em outros? Entendemos que nem todos possuem predisposição ou até mesmo interesse pelo assunto do qual ela trata, o que é natural, uma vez que estamos inseridos em um ambiente plural, com afinidades e diferentes inteligências, todavia, cabe perguntar se o desinteresse que algumas vezes é relacionado a Geografia - a própria desvalorização da mesma nos projetos curriculares e infelizmente, também, nas bases curriculares de nossos governos - não se dá porque não trabalhamos com ela de modo que vá ao encontro do aluno e de sua vivência, assim, o mesmo não percebe sentido ao aprendê-la.

\subsection{A Geografia Cultural: Nossa bagagem teórica para a busca de sentido}

Para que possamos atestar os caminhos para o encontro do sentido e favorecer a relação com os conceitos da Geografia, é preciso ter claro sob a partir de quais referências conceituais estamos trabalhando, partindo destes pressupostos de aproximações teóricas e buscando as relações entre o trabalho com o sentido abordado por Frankl (1988) dentro da Logoterapia, já discutida anteriormente, com o ensino de Geografia, para isso precisamos definir quais linhas teóricas fundamentam nosso modo de estudar esta ciência. Nos parece ser, até este momento, a Geografia Cultural, a linha teórica que melhor se enquadra e contribui com as problemáticas do ser humano e de sua existência, os 
modos de produção dos povos, atrelados a influência do meio e estudados pela Geografia Cultural, interessa a nós, sobretudo por conta de sua preocupação com a formação e a existência do ser humano.

A preocupação da Geografia Cultural com a formação dos sujeitos e a relação do espaço como elemento matriz de formação dos seres e organização entre si coloca o local de habitação como elemento importante do modo de organização das comunidades, neste sentido, o espaço habitado torna-se mais que um cenário somente, ele é elemento constituinte das histórias de quem nele habita, não é mais o "pano de fundo" das ações que o ser humano provoca ou o "receptor" dos objetos que estão postos, mas parte integrante da existência dos sujeitos e de suas ações. Nascendo inicialmente com o intuito da descrição da terra, como denuncia a etimologia de seu nome, a Geografia passou, a partir do século XVIII por uma transformação na busca de responder uma nova demanda que se apresentava: A relação do lugar habitado com os sujeitos ali presentes.

Neste sentido, os estudos da cultura parecem surgir como um caminho a ser investigado a partir dos grupos que desenvolveram tais costumes, levando em consideração os modos de viver e de se expressar em determinados espaços, generalizar culturas nos levaria a perda dos detalhes e dos elementos únicos que as constituem. Cabe questionar ainda, a partir de quais pontos de análise da existência humana podemos identificar e estudar a Geografia e a relação com a vida dos sujeitos, para Claval (2014), a experiência coletiva entre dos seres está ligada a gênese da cultura, para ele, a cultura é feita também de gestos, a maneira como nos comportamos são incutidas desde nossa tenra idade e repercutem durante nossa vida principalmente pelo modo como vemos o mundo e falamos dele. Divide então, em cinco categorias: 1 - A apreensão do mundo e da sociedade é feita através dos sentidos; 2 - Das representações se passa a conjuntos de ideias que organizam o mundo; 3 Recebemos de nosso entorno um sistema hierarquizado de preferências de valores; 4 - Os valores estruturam-se em um conjunto de crenças e de normas abstratas de comportamento e 5 - As ideologias pretendem-se construções laicas e racionais que dão um sentido à história e garantem a ordem social e a felicidade dos povos.

A questão dos valores, da apreensão e percepção do mundo e os comportamentos que determinado indivíduo possui diante da realidade posta também é abordada por Frankl (2008), quando problematiza a essência da existência do ser humano e indica que por sua noção de responsabilidade, buscamos constantemente a realização do sentido potencial de nossas vidas no que ele denomina de "autotranscendência da existência humana", ela "denota o fato de que o ser humano sempre aponta e se dirige para algo ou alguém diferente de si mesmo - seja um sentido a realizar ou outro ser humano a encontrar" (FRANKL, 2008, p. 135). Percebemos portanto, a importância da cultura na manutenção da vida social dos homens, afinal, ela permite a inserção no tecido social e "dá uma significação à sua existência e à dos que o circundam e forma a sociedade da qual este indivíduo se sente membro" (CLAVAL, 2008, p. 97), nos parece até o momento que a cultura está presente durante toda a formação dos sujeitos, porém, de formas variadas.

Através da Geografia Cultural parece que podemos nos alinhar com essa ideia, não desconsiderando as representações, mas comparando ainda mais as formas que estão presentes no espaço e a construção imaginária que os alunos possuem destas formas. Certamente sua história e o contexto social no qual estão inseridos irão modificar a forma como uma mesma situação é apreendida pelos alunos. Um ponto para refletirmos talvez seja as discussões de âmbito político que possuem contornos diferentes claros conforme o contexto social e de estrutura financeira que estão.

\subsection{0 sentido e sua busca pela Logoterapia: Uma aproximação com a Geografia}

A obra de Frankl (2008), resultando na formulação da Psicoterapia, denominada de Logoterapia, trabalha com o sentido a partir da fenomenologia do "homem-comum" frente às situações da vida, ou seja, como ele encara os desafios do cotidiano. Pensando nesses desafios que aparecem durante nossa vida e a maneira como lemos o mundo a partir delas o autor destaca três caminhos que, pensamos neste momento, talvez poderem ser também possibilidades para a sala de aula, uma vez que a 
Geografia é também uma matéria de "diversidade" e de situações múltiplas, os três caminhos podem servir de possibilidades para o planejamento e carecem de maior aprofundamento destas possibilidades, mas a princípio são: Valores de criação, valores de experiência e valores de atitude.

- Valores de criação: São os valores que trabalham com a autonomia dos sujeitos e sua capacidade autoral para os desafios impostos, a busca por soluções a partir de sua criatividade. Os valores de criação estão ligados a ação humana sobre o mundo, são respostas concretas. Um aluno que em uma aula de Geografia descobre-se autor, percebe-se, para Frankl, insubstituível e única. Experimenta a vida como missão no mundo. Cabe a nós, pensarmos em possibilidades que favoreçam a autonomia e a criatividade dos sujeitos em aula, propormos atividades que sejam co-autores e perceber essa valorização dentro do processo de ensino-aprendizagem. Conceito de relação com a Geografia: Espaço Geográfico.

- Valores de vivência: São realizados quando a pessoa toma algo do mundo, seja através da bondade, da verdade, da justiça ou mesmo do contato com a natureza ou do olhar cuidadoso sobre uma obra de arte ou uma paisagem. Esta vivência não é somente emocional, mas também intencional. Buscar a intencionalidade das paisagens e do que está posto, refletir sobre a formação da estrutura que é colocada. Apesar de aparentemente ser subjetiva, está atrelada ao externo como recebemos e percebemos o mundo. Percebemos isso nos nossos trabalhos de campo ou em momentos de desafios de observação, com olhar uma paisagem e procura distinguir seus elementos. Tal cuidado com o olhar e a descoberta do mundo e do desequilíbrio que muitas vezes temos nesse olhar é reforçado por Frankl quando diz que "no assombro ou admiração, o mundo pode aparecer à luz da possibilidade de ser conhecido ou investigado, de modo que conhecimento e valor são complementares e assim devem ser trabalhados na educação." Conceito de relação com a Geografia: Paisagem.

- Valores de atitude: Refere-se a postura que os sujeitos assumem perante situações de limite, de dificuldades no mundo, as desigualdades que existem, o contexto das guerras, o olhar que existe dos sujeitos através da tragédia, o contexto da violência urbana. Esse conceito de valor existe independente de religião, nem existe necessariamente relação moral ou ética, mas sim a problematização diante do sofrimento do outro. Conceito de relação com a Geografia: Lugar.

Avaliamos ser a partir de Frankl e estes pilares para o encontro do sentido e a relação com a vida que poderemos buscar caminhos metodológicos para pensarmos na presença ou não de sentido na sala de aula, começamos a perceber que temas da Geografia e dos caminhos do sentido, segundo a Logoterapia começam a ser cruzados de maneira natural.

Auxiliados pela concepção da Geografia Humanista e Cultural, temos na valorização do ser humano e na maneira como enxerga e manifesta o mundo suporte teórico para buscarmos tais relações, no caminho para o sentido e para sua presença nas aulas de Geografia podemos pensar na articulação dos conceitos como etapas para a próxima etapa que seria a construção do conhecimento/encontro de sentido na aula, ambos articulados pelo elemento vida.

\subsection{Entre o sentido e a Geografia: Algumas propostas}

A partir dos entrelaces teóricos construídos até este momento, ilustramos, através do resumo de duas atividades como o professor de Geografia poderia trabalhar alguns conceitos da Geografia, considerando os caminhos para o sentido sugeridos por FRANKL (2008):

Atividade 1: Revista geográfica.

Resumo da atividade: Elaborar uma revista nas mesmas estruturas das edições do segmento de variedades, esta atividade que deverá ser feita em grupos de 3 alunos, deverá ter como capa da edição alguma manchete da semana e na matéria de capa, os alunos deverão mostrar de maneira criativa, o maior número de temas relacionados a Geografia que eles conseguirem abstrair da notícia escolhida pelo grupo. A proposta é de uma revista moderna, de linguagem ágil e textos curtos. 
Eixos trabalhados: Espaço Geográfico/Criação.

Além da matéria de capa, os alunos deverão desenvolver alguma coluna na revista de curiosidades locais, sendo ilustradas por fotos registradas pela própria turma.

Eixos trabalhados: Lugar/Vivência.

Por fim, a revista deverá ter uma matéria de denúncia, onde os alunos deverão em uma imagem ilustrar um problema que eles encontrem, seja no bairro, na cidade, no país ou no mundo. 0 principal é este problema estar claro na imagem escolhida, de modo que quem a observe, identifique a denúncia já antes do texto (esta dinâmica de descobrir o problema pela imagem poderá ser feita separadamente, antes deles usarem as imagens nas revistas). Além da imagem e da denúncia do problema, os alunos deverão apresentar alguma solução para ele.

Eixos trabalhados: Paisagem/Atitude.

Atividade 2: Espelho da cidade.

Resumo da atividade: O Professor trará algumas imagens da cidade onde está inserida a escola, tais imagens deverão ser alternadas entre aspectos positivos e negativos da cidade. Cada grupo, formado por três pessoas, pegará uma sequência de 5 fotos, com paisagens diferentes e em um painel de papel pardo irão reproduzir as imagens através de desenho, modificando os problemas que eles acreditem estarem presentes nas imagens.

Posteriormente, o professor deverá juntar todos os painéis que foram produzidos e pendurá-los nas paredes, de modo que um complemente o outro e dê uma visão geral da cidade. Identificar junto com os alunos quais locais foram desenhados, quais mudaram para melhor e debater quais soluções poderiam ser tomadas para buscarmos melhorias na prática em nossa cidade.

Eixos trabalhados: Espaço Geográfico/Paisagem/Lugar/Criação/Vivência/ Atitude.

\section{Considerações (não tão) finais}

0 ensino de Geografia nos parece um desafio constante. Buscar compreender, mesmo que provisoriamente as realidades das salas de aula é um desafio que exige constante atualização por parte do professor. A sugestão pelo trabalho com o sentido da Geografia é antes, uma proposta teórica de oxigenação do ensino, buscando em outras áreas do saber, recursos técnicos que auxiliem nas práticas docentes. Pensamos, neste momento, que a formulação de aulas que (re)conheçam os elementos da Logoterapia para o encontro de sentido, possam ser aulas que privilegiem também as práticas dos saberes, queremos valorizar a teoria da Geografia ao aplicarmos na vida de quem a estuda, caso contrário, corremos o risco de ficarmos presos em suposições teóricas que não enxergam o espaço vivido de quem vive o espaço da sala de aula.

0 trabalho com o sentido na sala de aula de Geografia, provoca o professor a (re)pensar onde estão sendo inseridas as vidas dos alunos nos conteúdos que estão previstos para esta disciplina. A Geografia possui um objeto de estudo, o espaço, tão próximo de nossas vivências e, muitas vezes, perdemos as oportunidades de articular estas experiências dos alunos com os conteúdos que, falam das próprias vidas deles. Esse distanciamento entre a Geografia e o espaço vivido faz com que muitas vezes a disciplina perca o sentido para quem aprende, queremos ouvir o aluno, entender como a Geografia pode ter maior significado para ele. Sabemos o quanto essa ciência é importante para a formação cidadã e intelectual de nossos jovens, devemos portanto mostrar essa importância através de aulas que tenham sentido para quem aprende e quem ensina, auxiliando em um processo de ensino cada vez mais dinâmico e instigador. 


\section{Referências}

CASTROGIOVANNI, Antonio Carlos; TONINI, Ivaine Maria; GOULART, Lígias Beatriz Goulart; KAERCHER, Nestor André; MARTINS, Rosa Elisabete Militz Wypyczynski. O Ensino de Geografia e suas composições curriculares. Porto Alegre. Editora Mediação, 2014;

CLAVAL, Paul. A Geografia Cultural. Florianópolis. Editora UFSC. 2014.

FRANKL, Viktor Emil. Em busca de sentido: Um psicólogo no campo de concentração. São Leopoldo: Sinodal; Petrópolis: Vozes. 2008.

MORIN, Edgar. Introdução ao Pensamento Complexo. Editora Sulina. Porto Alegre, 2015.

O método 3: o conhecimento do conhecimento. Editora Sulina. Porto Alegre, 2003. 